\title{
What Contributes to Stigma Towards Autistic University Students and Students with Other Diagnoses?
}

\author{
Kristen Gillespie-Lynch ${ }^{1,2}$ (1) $\cdot$ Nidal Daou $^{3,7} \cdot$ Rita Obeid $^{1,2,8} \cdot$ Siobhan Reardon ${ }^{4} \cdot$ Spogmay Khan $^{1,6}$. \\ Emily J. Goldknopf ${ }^{5}$
}

Published online: 5 June 2020

○) Springer Science+Business Media, LLC, part of Springer Nature 2020

\begin{abstract}
Little remains known about the degree to which autistic university students are stigmatized relative to students with other diagnoses. We conducted an online survey with students in New York City $(n=633)$ and Beirut $(n=274)$. Students with diagnoses that were perceived as dangerous (e.g., psychopathy) were more stigmatized than students with diagnoses that were perceived as less dangerous (e.g., autism). Disruptive autistic behaviors (described via vignettes) evoked more stigma than withdrawn behaviors. Perceived dangerousness predicted autism stigma. Greater acceptance of inequality, less openness, and lower cognitive empathy co-occurred with heightened stigma towards most conditions. Diagnostic labels were typically less stigmatized than behaviors. Findings suggest that interventions are needed to decrease stigma towards varied diagnoses in collegiate communities.
\end{abstract}

Keywords Autism $\cdot$ Learning disability $\cdot$ ADHD $\cdot$ Stigma $\cdot$ College $\cdot$ University $\cdot$ Neurodiversity $\cdot$ Empathy

Growing numbers of autistic ${ }^{1}$ individuals are enrolling in universities $^{2}$ (Bakker et al. 2019). Emerging literature suggests that autistic university students may often have academic strengths relative to their non-autistic peers (Bakker et al. 2019; Gillespie-Lynch et al. in press; Sturm and Kasari 2019). Yet, they may face challenges adapting to collegiate

Electronic supplementary material The online version of this article (https://doi.org/10.1007/s10803-020-04556-7) contains supplementary material, which is available to authorized users.

Kristen Gillespie-Lynch

kgillyn@gmail.com

1 College of Staten Island, City University of New York, Staten Island, NY, USA

2 The Graduate Center, City University of New York, New York, NY, USA

3 American University of Beirut, Beirut, Lebanon

4 Independent Scholar, Burlington, VT, USA

5 University of California, Los Angeles, USA

6 College of Staten Island, Staten Island, USA

7 Present Address: McNeese State University, Lake Charles, LA, USA

8 Present Address: Case Western Reserve University, Cleveland, $\mathrm{OH}, \mathrm{USA}$ life, including social isolation, bullying, and/or mental health issues (Connor 2013; Gelbar et al. 2015; Jones et al. 2013; McMorris et al. 2019). Although autistic university students report that bullying is less common in adulthood relative to earlier in development (DeNigris et al. 2018), non-autistic university students may quickly form negative first impressions of autistic adults (Sasson et al. 2017), particularly when they are not informed that they have a disability (Morrison et al. 2019).

To help make collegiate communities more supportive of autistic students, a growing body of research examines attitudes towards autism among university students

\footnotetext{
$\overline{1}$ Throughout this manuscript, we use identity-first language (e.g., autistic people) rather than person-first language (e.g., people with autism) because identity-first language is preferred by the majority of autistic participants in existing studies evaluating preferences [e.g., Kapp et al. (2013); Kenny et al. (2016)]. Identity-first language may also be less likely to contribute to stigma (Gernsbacher 2017).

2 In this manuscript, we use the terms "university" and "college" interchangeably as both terms have the same general meaning (i.e., a postsecondary institution) in the United States (US). We primarily use the term "university" since in some countries, such as the United Kingdom, "college" signifies an institution that people attend before they attend university. We occasionally use the term "college" to avoid neglecting the experiences of the majority of autistic students who seek postsecondary education in the US, most of whom, at least initially, attend a community college (where one can obtain an associate's degree; Wei et al. 2014).
} 
(Gardiner and Iarocci 2014; Nevill and White 2011; Tipton and Blacher 2014; White et al. 2016) and evaluates trainings to reduce stigma (Gillespie-Lynch et al. 2015; Obeid et al. 2015; Someki et al. 2018). Such work has revealed that university students who report more negative first impressions of autistic people express limited autism knowledge and reduced willingness to engage with autistic people (or heightened social distance, a measure of stigma) relative to their more accepting peers. Students who desire more social distance from autistic people are more likely to be male and to express less autism knowledge, less openness to experience, and more acceptance of inequality (or the belief that hierarchies favoring some groups over others are justified; Gillespie-Lynch et al. 2019). However, little is known about the degree to which autistic students are stigmatized relative to students with other diagnoses. The current study aims to compare stigma towards autistic university students with stigma towards students with other diagnoses and to identify characteristics that contribute to stigma towards varied conditions.

Stigma is a multifaceted construct defined by Goffman (1963; pp. 3-5) as an attribute that is "deeply discrediting" because others interpret it as an "undesired differentness from what we ["the normals"] had anticipated." Link and Phelan (2001) defined stigma as a process that is rooted in and exacerbates power inequalities by identifying and labeling differences, associating a label with a negative stereotype, distinguishing between "us" and "them", and discriminating. The degree to which diagnostic labels and/ or behaviors associated with diagnoses contribute to stigma has been the focus of extensive debates. Early proponents of "labeling theory" speculated that diagnostic labels were the primary cause of stigma towards mental illnesses (Scheff 1975). In response to evidence that behaviors associated with diagnoses may contribute to stigma more than labels (Gove 1975), later adaptations of labeling theory asserted that labels activate pre-existing stereotypes, increasing stigma when the label is perceived as dangerous and decreasing stigma when the label is not perceived as dangerous (Link et al. 1987).

Corrigan (2007) asserted that diagnostic labels can function as cues differentiating a minority group from a majority group and activating stereotypes (e.g., the diagnostic criteria), thus engendering stigma. "Although diagnostic systems are developed by social work and other mental health professionals to better understand mental illness, they unintentionally exacerbate the stigma of mental illness" (p. 37). To alleviate stigma, Corrigan recommended replacing categorical diagnoses with dimensional ratings. Although the National Institute of Mental Health (NIMH) also prefers dimensional over categorical approaches to diagnosis (Insel 2014), albeit for different reasons than Corrigan, the DSM-5 continues to rely on categorical diagnoses (APA 2013). The current study evaluates whether categorical labels contribute to or ameliorate stigma towards a range of conditions.

Researchers most commonly assess stigma using social distance scales, first developed by Bogardus in the 1920s to assess attitudes toward racial/ethnic minorities (Jorm and Oh 2009; Link et al. 2004). Heightened desire for social distance is often associated with less knowledge about and contact with a condition, as well as with greater belief that it is dangerous (e.g., Link et al. 1987; Schomerus et al. 2014). A large body of research supports Link's theory that labels engender stigma through associations with perceived dangerousness. Random assignment of the label "mental patient" to a vignette leads to heightened social distance (Jackson and Heatherington 2006). When participants identify unlabeled vignettes depicting mental illnesses with terms like "mental illness" or "psychosis", they report heightened desire for social distance from and/or greater belief that characters in the vignettes are dangerous (Bag et al. 2006; Lauber et al. 2004; Martin et al. 2000; Phelan and Basow 2007; Wright et al. 2011; Yap et al. 2013). Perceived dangerousness may mediate associations between labeling someone as "mentally ill" and social distance (Martin et al. 2000, 2007).

Deep rooted beliefs about dangerousness may foil attempts to reduce stigma. Indeed, nationally representative interviews conducted in the US in 1960 and 1996 revealed increases in the perceived dangerousness of psychosis despite improved ability to identify disorders and public support for help seeking (Phelan et al. 2000). Pescosolido et al. (2010) used interviews in 1996 and 2006 to assess the impact of widespread anti-stigma initiatives in the US. No decreases in stigma towards schizophrenia, depression, or alcohol dependence were observed. A majority of the public continued to indicate that they did not want to work with a person with any of the conditions. Similar nationally representative interviews conducted in Germany in 1990 and 2011 revealed that desired social distance from schizophrenia increased with time while social distance from alcoholism and depression remained relatively stable (Angermeyer et al. 2013). Fear of schizophrenia and the belief that it was biological in origin also increased. Public attitudes toward mental illness also appeared to become less positive in England and Scotland between 1994 and 2003 despite a widespread anti-stigma campaign, which unfortunately coincided with intensification of media discussions linking violence and mental illness (Mehta et al. 2009). Participants increasingly indicated that people with mental illness do not deserve our sympathy and are a burden on society.

In contrast to the aforementioned evidence that stigma towards mental illnesses may be worsening, increasing acceptance of autism was recently observed among students at a university in the US over a smaller span of 5 years (White et al. 2016). Accurate labeling has been associated with reduced stigma towards autism and other 
neurodevelopmental disorders, such as stuttering and intellectual disabilities (Boyle et al. 2017; Sasson and Morrison 2019; Scior et al. 2013). While one study found similar benefits of labeling autistic behaviors as "schizophrenia" or "autism" (Brosnan and Mills 2016), another study found that the label "autism" positively impacted first impressions of people exhibiting autistic behaviors while the label "schizophrenia" did not (Sasson and Morrison 2019). Indeed, a study with a general population sample in Denmark revealed heightened stigma towards the label "schizophrenia" relative to "autism"; "schizophrenia" was associated with dangerousness while autism was associated with intelligence (Jensen et al. 2016). Similarly, adults from a market research panel in France rated the label "schizophrenia" with the highest social distance (it was also rated most dangerous) followed by "bipolar disorder", and "autism" (Durand-Zaleski et al. 2012). Prior findings align with Link's adaptation of labeling theory by suggesting that stigma towards diagnoses that are perceived as less dangerous is lower and more likely to improve than stigma towards conditions that are perceived as more dangerous.

To identify factors that contribute to stigma towards varied disorders, Feldman and Crandall (2007) developed vignettes describing individuals with 40 mental disorders. They asked university students enrolled in an introductory psychology course to rate the vignettes on 17 dimensions (e.g., dangerousness to others, treatability, heritability, responsibility, rarity, etc.) and to indicate their willingness to engage using a social distance scale. Participation was voluntary so the number of ratings for each condition varied; a mean of 13.5 students rated each condition. Means for each condition were the focus of analyses. The highest social distance ratings were reported for antisocial personality disorder, pedophilia, and factitious disorder. The lowest social distance ratings were reported for autism, posttraumatic stress disorder, female sexual arousal disorder, and narcolepsy. When all 17 dimensions were entered into a regression analysis predicting mean social distance ratings, heightened perceived responsibility, dangerousness, and rarity predicted stigma. The authors indicated that rarer conditions may be more stigmatized because people have fewer opportunities for high-quality contact with people with that condition; high-quality contact is commonly associated with reduced stigma (Corrigan et al. 2007).

Feldman and Crandall (2007) interpreted associations between perceived personal responsibility and stigma as evidence for attribution theory, which states that harsh responses arise when negative behaviors are attributed to controllable factors (e.g., personal choices) rather than to uncontrollable factors like genetics (Weiner et al. 1988). In line with attribution theory, anti-stigma interventions often highlight biogenetic explanations to absolve people of responsibility for their symptoms. Unfortunately, recent evidence suggests that biogenetic explanations can essentialize differences between people with and without a condition and thus promote perceptions of dangerousness by suggesting that the condition is outside of a person's control (Angermeyer et al. 2011; Haslam 2000; Hinshaw and Stier 2008; Jorm and Griffiths 2008; Kermode et al. 2009). Endorsement of biogenetic causes has been associated with reduced stigma towards alcoholism (in line with attribution theory) but heightened stigma towards schizophrenia and/or depression (Schomerus et al. 2014). Associations between perceived responsibility and stigma are far less consistently observed than associations between perceived dangerousness and stigma (Angermeyer et al. 2011; Corrigan et al. 2002).

Although Feldman and Crandall's (2007) study was a relatively comprehensive comparison of stigma towards a range of disorders, there were obvious limitations in the sampling and analytic approach. In addition, the vignettes they developed depicted the most common characteristics associated with each disorder (e.g., the most common age, gender, and prognostic outcome for a given disorder). Their approach to creating vignettes made it impossible to distinguish between stigma arising from core characteristics of each disorder, labels for each disorder, and/or commonly co-occurring characteristics.

Nevertheless, similar patterns to those observed by Feldman and Crandall (2007) have been observed in other studies. Using interviews about unlabeled vignettes, Link et al. (1999) found that participants in the US rated substance abusers as most likely to be violent, followed by people with schizophrenia and then people with depression. The pattern of desired social distance mirrored perceived dangerousness. Another general population sample in the US also expressed heightened social distance towards unlabeled vignettes depicting substance abuse relative to schizophrenia followed by depression (Martin et al. 2000). Participants in Australia and Switzerland reported heightened social distance towards unlabeled vignettes depicting schizophrenia relative to depression (Griffiths et al. 2006; Jorm and Griffiths 2008; Lauber et al. 2004). In the United Kingdom, participants reported increased social distance toward an unlabeled vignette depicting schizophrenia relative to intellectual disability (Scior et al. 2013). In South Korea, participants reported heightened social distance and greater perceptions of dangerousness toward vignettes depicting substance abuse, followed by schizophrenia, and depression (Lee and Seo 2018).

Associations between labels, perceived dangerousness, and/or stigma are likely to be affected by culture. Angermeyer et al. (2005) presented an unlabeled vignette depicting a person with schizophrenia to representative samples in Germany, Russia, and Mongolia. German respondents who identified the character in the vignette as "mentally ill" rated 
the character as more dangerous. Conversely, no associations between identifying the character as "mentally ill" and dangerousness were observed in Russia or Mongolia. Desired social distance towards unlabeled vignettes depicting schizophrenia and depression was also higher in Japan relative to Australia (Griffiths et al. 2006). Japanese participants were more likely to describe schizophrenia as dangerous relative to Australians (Reavley and Jorm 2011). The first studies to compare stigma towards autism across cultures revealed higher social distance towards the label "autism" in Japan relative to Lebanon with the lowest stigma reported among university students in the US (Gillespie-Lynch et al. 2015; Obeid et al. 2015; Someki et al. 2018). A follow-up study found that heightened stigma among students in Lebanon relative to the US was initially replicated but was no longer significant after autism knowledge, quality of contact with autistic people, openness to experience, and acceptance of inequality were accounted for (Gillespie-Lynch et al. 2019). Emotional intelligence was unrelated to autism stigma. To the best of our knowledge, no prior research has examined potential associations between empathy and autism stigma, despite evidence that reduced empathy is associated with generalized prejudice (Bäckström and Björklund 2007).

The present study compares stigma towards students with the following conditions among university students in the US and Lebanon: withdrawn and disruptive autism, learning disability (LD), ADHD, social anxiety, depression, mania, eating disorders, addiction to pain medication, psychopathy, and schizophrenia. We hypothesized that stigma would be highest towards psychopathy (due to heightened perceived dangerousness and responsibility) with the following disorders stigmatized to a decreasing degree in the US: pain medication addiction, schizophrenia, depression, eating disorders, mania, autism (with disruptive autism more stigmatized than withdrawn autism), learning disabilities, ADHD, and social anxiety. In Lebanon, we expected stigma to be heightened toward psychopathy and schizophrenia, to be moderate toward autism, and to be lowest for anxiety and eating disorders (which are common in Lebanon; Khawaja and Afifi-Soweid 2004; Soweid et al. 2002).

We expected stigma to be heightened in Lebanon relative to the US (as found by Obeid et al. 2015). We expected heightened acceptance of inequality and reduced cognitive empathy, or perspective taking, to be associated with heightened stigma based on research linking acceptance of inequality with autism stigma (Gillespie-Lynch et al. 2019) and reduced empathy to social distance towards depression, substance abuse, and common stress (Foster et al. 2018; Phelan and Basow 2007).

Participants were randomly assigned to view either unlabeled vignettes, labeled vignettes, or diagnostic labels. We hypothesized that behaviors associated with a disorder would typically be more stigmatized than diagnostic labels but that labels might be more stigmatized than behaviors when the label itself is perceived as dangerous (Link et al. 1987). We expected stigma toward diagnostic labels plus behaviors would be lowest (as the condition with the highest information to guide decision making).

\section{Method}

\section{Participants}

Undergraduate students at two urban universities, a university with unselective admissions criteria in New York City ( $n=633$; approximate total undergraduate population 12,$211 ; 5.18 \%$ ) and a more selective university in Lebanon ( $n=274$; approximate total undergraduate population 7341 ; $3.73 \%$ ), were invited to enroll in an online survey study for academic credit. Participants, 18 years of age or older, completed an IRB approved online consent form before starting the survey. See Table 1 for demographic characteristics of the participants in each country.

\section{Materials}

All study measures were administered online. All procedures performed in studies involving human participants were in accordance with the ethical standards of the institutional and/or national research committee (2017-0869) and with the 1964 Helsinki declaration and its later amendments or comparable ethical standards. After completing an online consent form, participants filled out a demographics questionnaire and were randomly assigned to rate vignettes (a brief story about a college student with a disorder that described behaviors associated with the disorder but did not include a diagnostic label; Appendix A), diagnostic labels (e.g., "a college student with depression"), or vignettes plus diagnostic labels (the aforementioned vignettes with the condition labeled). Each student rated ten distinct conditions (withdrawn and disruptive autism, learning disability, ADHD, social anxiety, depression, mania, addiction to pain medication, eating disorder, psychopathy, and schizophrenia). Due to the diversity of the autism spectrum, we included two vignettes about autism, depicting a withdrawn and a disruptive autistic college student. Vignettes were developed primarily by a co-author who identifies with six of the conditions surveyed, including autism, and were then revised by the other co-authors.

\section{Demographic Survey}

Participants were asked to indicate their age, gender, major (classified as helping majors if education, nursing, 
Table 1 Comparisons of participant characteristics across countries

\begin{tabular}{lllll}
\hline & United States $(n=633)$ & Lebanon $(n=274)$ & Significance & Effect size \\
\hline \% Male & 43.6 & 46.5 & $p=.42$ & $r=.03$ \\
\% White & a & 83.3 & $p<.001$ & $r=.38$ \\
\% Helping major & a & 10.2 & $p<.001$ & $r=.32$ \\
Age $^{\mathrm{a}}$ & 42.8 & $18.75(2.03)$ & $p<.001$ & $d=.35$ \\
Autism knowledge $_{\text {Vertical orientation }}$ & $19.79(3.72)$ & $14.10(7.85)$ & $p=.53$ & $d=.03$ \\
Cognitive empathy $^{\mathrm{a}}$ & $-6.14(6.96)$ & $-6.04(7.24)$ & $p=.86$ & $d=.01$ \\
Openness $^{\mathrm{a}}$ & $7.48(4.57)$ & $8.57(3.96)$ & $p<.001$ & $d=.25$ \\
Social desirability bias $^{\mathrm{a}}$ & $6.32(6.03)$ & $8.74(6.44)$ & $p<.001$ & $d=.39$ \\
Autism symptoms $^{\mathrm{b}}$ & $13.32(2.65)$ & $6.36(2.54)$ & $p=.86$ & $d=.01$ \\
\hline
\end{tabular}

${ }^{\mathrm{a}}$ Indicates group differences that are significant at the alpha level of .001 selected for this study

${ }^{\mathrm{b}}$ Autism symptoms were assessed with the RAADS-14 occupational/physical therapy, pre-med, psychology, or social work were reported), and country of residence (US vs. Lebanon).

\section{Evaluations of Labels and/or Vignettes}

After reading each label and/or vignette, participants were asked to complete a social distance scale, an open-ended description of each condition, "How would you define this student's condition?" and evaluations of each condition; Please evaluate this student's condition: "How common do you think it is?", "How dangerous to others do you think it is?" and "How responsible for it do you think the student is?" The rating scales for perceived commonness, dangerousness, and responsibility ranged from 0 (not at all) to 100 (very much so). They were also asked to reflect on their prior types and quality of contact with each condition.

\section{Social Distance Scales}

The measure of stigma used in the current study was an adapted version of the Social Distance Scale (Bogardus 1933), a commonly used measure of stigma that typically exhibits good internal consistency and evidence of validity (Link et al. 2004). To ensure that random responding was not driving cross-cultural differences, we adapted the 6-item autism stigma scale (with no reverse-scored items) used in prior work (e.g., Gillespie-Lynch et al. 2015; Obeid et al. 2015) to include 3 reverse scored items; see Appendix B). We also expanded the response scale used in prior work from a 5-level Likert scale to a 7-point Likert scale (i.e., -3 strongly disagree, -2 disagree, -1 somewhat disagree, 0 neither agree nor disagree...to 2 strongly agree); stigma scores could range from -18 to 18 with higher scores indicating heightened stigma. The internal consistency of our adapted social distance scales remained good in the current sample ( $\alpha=.78$ to .88 across conditions).

\section{Type and Quality of Contact}

Participants were asked to share their personal experiences with each condition: 'Please select as many of the following types of relationships as you have had with individuals with this student's condition: yourself, your child, your parent, your sibling, your spouse, your extended family member, your friend, your coworker, your student, your fellow student, your acquaintance, or other.' Participants also rated the quality of their prior contact with each condition using a Likert scale item adapted from Gardiner and Iarocci (2014): "In the past, your experiences with individuals with this student's condition have been pleasant." The same 7-point Likert scale was employed for this as for the social distance scales.

\section{Autism Awareness Survey}

This measure of autism knowledge was adapted from an original 13 item scale created by Stone (1987). We added items to the scale to capture new changes in the diagnostic criteria and to attempt to improve upon its internal consistency, which was low in prior research (e.g., US $\alpha=.68$; Lebanon $\alpha=.62$; Gillespie-Lynch et al. 2019). Participants were asked to rate 29 statements about autism using a 5-point Likert scale (i.e., -2 for strongly disagree to 2 for strongly agree); 11 items were reverse scored). Internal consistency was numerically slightly higher relative to prior work (US $\alpha=.72$; Lebanon $\alpha=.66$ ). The total autism knowledge score could range from -58 to 58 with a higher score indicating more accurate knowledge.

\section{Basic Empathy Scale in Adults (BES-A)}

The (BES-A), assessing cognitive and affective empathy (Carré et al. 2013; Jolliffe and Farrington 2006), is a 20-item self-report questionnaire. Participants use a five-point Likert 
scale, with responses ranging from 1 (strongly disagree) to 5 (strongly agree), to rate statements about both cognitive empathy (e.g., "When someone is feeling 'down' I can usually understand how they feel") and affective empathy (e.g., "After being with a friend who is sad about something, I usually feel sad"). Nine items assess cognitive empathy (US $\alpha=.79$; Lebanon $\alpha=.73$ ), while 11 items assess affective empathy (US $\alpha=.82$; Lebanon $\alpha=.85$ ).

\section{Culture Orientation Scale (Triandis and Gelfand 1998)}

This 16-item measure consists of four 4-item subscales: vertical individualism (e.g., "Winning is everything."), vertical collectivism (e.g., "It is important to me that I respect the decisions made by my groups."), horizontal individualism (e.g., "I often do "my own thing."), and horizontal collectivism (e.g., "If a coworker gets a prize, I would feel proud."). Vertical orientation, or acceptance of inequality, was calculated by subtracting horizontal collectivism and individualism from vertical collectivism and individualism (Gillespie-Lynch et al. 2019). The internal consistency of the overall scale was acceptable (US $\alpha=.76$; Lebanon $\alpha=.75$ ).

\section{Openness to Experience (NEO Five Factor Inventory-3; McCrae and Costa 2007)}

Openness to experience (US $\alpha=.75$; Lebanon $\alpha=.75$ ) was assessed using a subscale of the NEO Five Factor Inventory-3 comprising 12 items (5 reverse scored). Higher scores indicate greater openness to experience.

\section{Short Marlowe-Crowne Social Desirability Scale (Reynolds 1982)}

This measure of social desirability bias (US $\alpha=.64$; Lebanon $\alpha=.59$ ) consists of 13 binary items (5 reverse scored). Higher scores indicate greater susceptibility to the social desirability bias.

\section{RAADS-14 (Eriksson et al. 2013)}

This 14-item measure (1 reverse-scored item) was designed to be a rapid autism screener (US $\alpha=.79$; Lebanon $\alpha=.68$ ). Higher scores indicate more autistic symptoms. Overall scores range from 0 to 42 . A score of 14 or above suggests heightened likelihood of autism.

\section{Analytic Approach}

Analyses were conducted using IBM SPSS Version 24. The social distance scales with reverse scored items did not exhibit excessive kurtosis, skew, or multicollinearity. However, perceived dangerousness of both withdrawn and disruptive autism were not normally distributed. Therefore, we log transformed these variables.

Independent sample $t$-tests (for continuous variables) and chi-square tests (for categorical variables) were used to examine differences between participants from Lebanon and the US (see Table 1). Exploratory correlations were used to identify individual differences that were associated with social distance to include in multivariate general linear models predicting stigma across conditions. Baseline correlations revealed associations between social distance scores and cognitive empathy, openness, vertical orientation, social desirability bias (only significant in relation to unlabeled behaviors associated with schizophrenia), gender, and country. No associations were observed between social distance scores and autism symptoms (assessed with the RAADS-14), age, or being in a helping major. Variables that were not significantly related to stigma were not included in further analyses.

A multivariate general linear model was conducted with gender, country, and random assignment as between subjects variables and social distance toward the conditions (including both withdrawn and disruptive autism) as the dependent variables. This analysis was then repeated with individual differences that had been associated with social distance towards autism (i.e., openness to experience and vertical orientation) and other conditions (i.e., cognitive empathy) in past research as covariates.

We visually inspected the average social distance scores toward each condition in each country in relation to the dimensions identified as predictors by Feldman and Crandall (2007): perceived dangerousness, responsibility, and rarity. Univariate and repeated measures analyses were used to examine contributors to stigma towards the label "autism" or toward unlabeled vignettes depicting withdrawn and disruptive autism. To protect against Type 1 error, we used an alpha level of .001 throughout. $P$-values for all significant findings are not indicated in the text but are equal to or less than .001 .

\section{Results}

\section{Were There Differences Between the Samples?}

Participants in Lebanon were younger, less likely to be in helping majors, and more likely to be white than participants in the US. They also reported heightened cognitive empathy and openness to experience. No differences in vertical orientation, social desirability bias, autism knowledge, gender, or autism symptoms were observed across samples (see Table 1). 

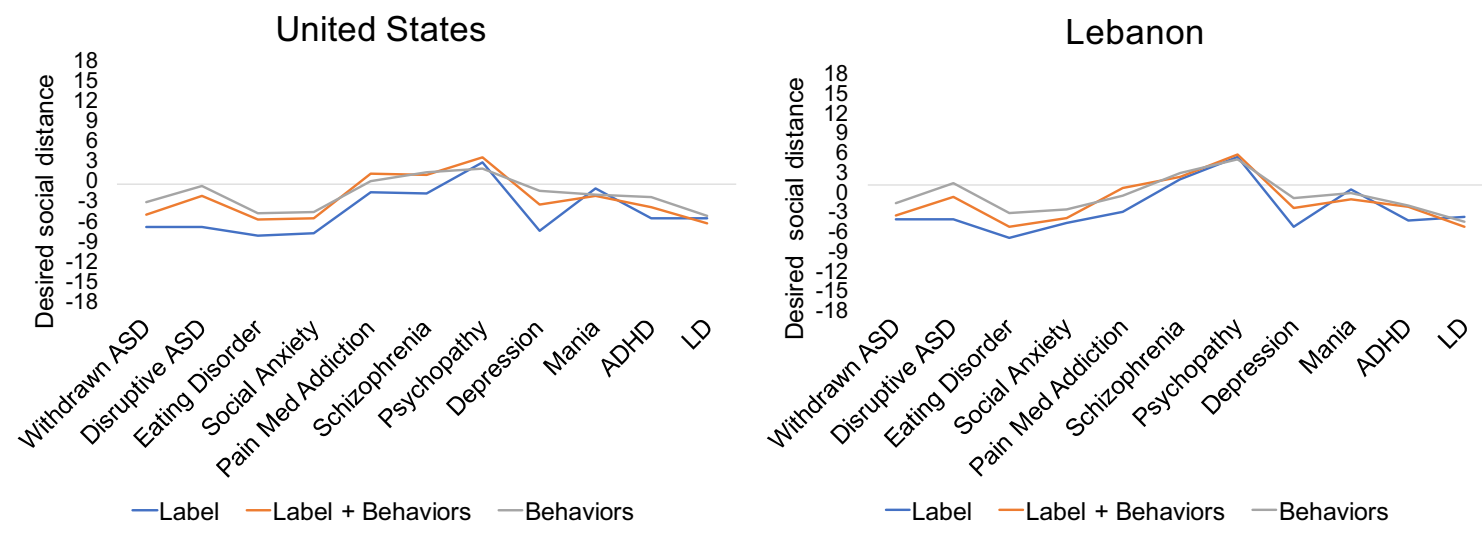

Fig. 1 Stigma toward university students with different diagnoses in the US and Lebanon

\section{Do Categorical Diagnostic Labels and/or Behaviors Contribute to Stigma?}

We conducted a multivariate general linear model with social distance toward different disabilities as multivariate variables and country, gender, and random assignment to label, vignette, or both as between subjects factors. A main effect of disorder was observed, $F(10,880)=132.21, \eta^{2}=.60$ (See Fig. 1). Stigma toward each condition could range from - 18 (lowest stigma) to 18 (highest stigma). Psychopathy was more stigmatized than all other conditions $(M=3.85$; $S E=.28)$, followed by schizophrenia $(M=1.03 ; S E=.27)$, then pain medication addiction $(M=-.97 ; S E=.26)$ and mania $(M=-1.51 ; S E=.23)$, followed by disruptive autism $(M=-2.67 ; S E=.23)$, followed by ADHD $(M=-3.98$; $S E=.23)$, depression $(M=-4.11 ; S E=.24)$, and withdrawn autism $(M=-4.67 ; S E=.22)$, followed by social anxiety $(M=-5.48 ; S E=.24), \mathrm{LD}(M=-5.76 ; S E=.23)$, and eating disorders $(M=-6.37 ; S E=.22)$.

Main effects of gender, $F(1,889)=24.71, \eta^{2}=.03$ and randomization to labels, behaviors, or labels and behaviors, $F(2,889)=18.68, \eta^{2}=.04$, were observed. Women $(M=-3.62 ; S E=.23)$ reported less stigma than men overall $(M=-1.94 ; S E=.25)$. Although women reported numerically lower stigma than males across conditions, this difference was only significant for withdrawn and disruptive autism, eating disorder, social anxiety, ADHD, and LD. Diagnostic labels $(M=-4.15$; $S E=.29)$ were less stigmatized than behaviors associated with conditions $(M=-1.70$; $S E=.29)$ or behaviors plus diagnostic labels $(M=-2.50$; $S E=.31$, which did not differ significantly from one another $(p=.06)$. Follow-up ANOVAs confirmed that unlabeled vignettes did not generally elicit significantly less stigma than labeled vignettes. However, for withdrawn and disruptive autism and for depression, labeled vignettes elicited significantly less stigma than unlabeled vignettes. Trends toward reduced stigma for labeled relative to unlabeled vignettes were observed for eating disorders $(p=.009)$, $\operatorname{ADHD}(p=.03), \operatorname{LD}(p=.03)$, and social anxiety $(p=.04)$. Trends toward heightened stigma for labeled relative to unlabeled vignettes were observed for psychopathy $(p=.03)$ and pain medication addiction $(p=.05)$.

An interaction was observed between social distance towards different disorders and randomization, $F(20$, $1762)=16.53, \eta^{2}=.16$. Follow up ANOVAs revealed that labels were significantly less stigmatized than behaviors for all conditions except psychopathy, mania, and learning disabilities. An interaction was also observed between country and social distance, $F(10,880)=7.12, \eta^{2}=.08$. Follow up $t$-tests revealed no country differences in preferred social distance toward any condition ( $p s>.11$ ), except reduced social distance towards pain medication addiction in Lebanon $(M=-2.26 ; S E=6.72)$ relative to the US $(M=.19$; $S E=7.53)$ and a trend toward heightened social distance towards psychopathy in Lebanon $(p=.04)$.

\section{Do Individual Differences Contribute to Social Distance Towards Different Diagnostic Labels?}

To examine the role of individual differences in predicting social distance, we then reran our multivariate linear model with the following variables that had been associated with social distance towards autism included as covariates: openness, vertical orientation, cognitive empathy, and social desirability bias. A main effect of disorder type was still observed, $F(10,876)=12.12, \eta^{2}=.12$, with the same pattern of differences in stigma towards different conditions reported above. Interactions between stigma and cognitive empathy, $F(10,876)=7.29, \eta^{2}=.08$, and stigma and social desirability bias, $F(10,876)=3.32, \eta^{2}=.04$, were observed. Follow up correlations revealed that heightened cognitive empathy was associated with significantly reduced social distance towards all conditions except the most stigmatized ones. Associations between cognitive empathy and social 
Table 2 Ratings of diagnostic labels in the US: Mean social distance; perceived commonness, dangerousness, and responsibility

\begin{tabular}{lllll}
\hline & Social distance & Commonness & Dangerousness & Responsibility \\
\hline Psychopathy & $3.27(8.37)$ & $38.03(24.47)$ & $62.86(31.38)$ & $31.02(26.27)$ \\
Mania & $-.79(6.94)$ & $37.53(27.72)$ & $43.10(27.28)$ & $27.92(25.49)$ \\
Pain medication addiction & $-1.32(7.59)$ & $57.47(26.02)$ & $62.04(31.36)$ & $53.08(28.77)$ \\
Schizophrenia & $-1.52(7.56)$ & $42.63(23.69)$ & $49.72(28.71)$ & $21.79(25.36)$ \\
LD & $-5.43(7.17)$ & $51.96(26.40)$ & $18.90(21.31)$ & $22.87(26.25)$ \\
ADHD & $-5.58(6.92)$ & $54.02(26.14)$ & $24.21(23.74)$ & $24.79(26.43)$ \\
Autism & $-6.91(6.03)$ & $51.32(25.59)$ & $20.25(22.99)$ & $25.11(28.70)$ \\
Depression & $-7.57(7.14)$ & $67.58(25.95)$ & $38.69(30.45)$ & $34.14(28.03)$ \\
Social anxiety & $-7.85(7.23)$ & $61.34(26.50)$ & $26.91(27.31)$ & $33.74(30.67)$ \\
Eating disorder & $-8.19(6.10)$ & $56.22(23.45)$ & $33.50(33.55)$ & $40.68(29.71)$ \\
\hline
\end{tabular}

Social distance scores for each condition could range from - 18 (lowest stigma) to 18 (highest stigma). Ratings of perceived commonness, dangerousness and responsibility could range from 0 (not at all) to 100 (very much so)

\begin{tabular}{lllll}
\hline & Social distance & Commonness & Dangerousness & Responsibility \\
\hline Psychopathy & $4.43(8.35)$ & $31.85(22.57)$ & $62.87(28.60)$ & $35.50(23.06)$ \\
Schizophrenia & $.89(7.46)$ & $30.69(20.64)$ & $52.54(25.89)$ & $22.97(21.49)$ \\
Mania & $-.82(7.02)$ & $30.73(19.35)$ & $40.34(26.70)$ & $32.01(22.13)$ \\
Medication addiction & $-4.34(6.82)$ & $46.14(24.74)$ & $46.90(29.56)$ & $54.55(23.68)$ \\
LD & $-5.17(6.38)$ & $42.91(22.48)$ & $13.41(18.52)$ & $18.81(20.03)$ \\
Autism & $-5.61(5.82)$ & $44.97(22.51)$ & $22.48(24.86)$ & $16.35(23.59)$ \\
ADHD & $-5.83(6.82)$ & $45.78(23.64)$ & $25.89(25.60)$ & $26.81(25.10)$ \\
Social anxiety & $-6.32(6.73)$ & $55.73(24.72)$ & $25.63(26.06)$ & $37.00(23.64)$ \\
Depression & $-6.89(6.68)$ & $60.53(25.38)$ & $31.39(16.48)$ & $42.50(25.07)$ \\
Eating disorder & $-8.59(5.73)$ & $53.93(22.74)$ & $21.94(29.43)$ & $36.65(25.61)$ \\
\hline
\end{tabular}

Social distance scores for each condition could range from - 18 (lowest stigma) to 18 (highest stigma). Ratings of perceived commonness, dangerousness and responsibility could range from 0 (not at all) to 100 (very much so)
Table 3 Ratings of diagnostic labels in Lebanon: Mean social distance; perceived commonness, dangerousness, and responsibility as were trends toward interactions between vertical orientation and stigma, $p=.003$, openness and stigma, $p=.01$, and stigma and gender, $p=.04$.

\section{Does Stigma Mirror Perceived Dangerousness, Personal Responsibility, and/or Rarity?}

As can be seen in Tables 2 and 3, perceptions of dangerousness more consistently (though not always) mirrored desire for social distance than perceived responsibility or commonness did. A general linear model $\left(R^{2}=.24\right)$ predicting stigma towards the label "autism" in particular revealed that greater perceived dangerousness, $F(1,301)=16.61, \eta^{2}=.05$, and vertical orientation, $F(1,301)=15.92, \eta^{2}=.05$, predicted heightened stigma toward the label "autism". A trend toward an association between thinking autism is more common and less social distance was observed $(p=.007)$, as were trends associating gender $(p=.02)$ and autism knowledge $(p=.009)$ with stigma. Country $(p=.06)$, perceived responsibility 
$(p=.08)$, openness $(p=.31)$, and cognitive empathy $(p=.65)$ were not related to social distance toward the label "autism".

A repeated measures general linear model predicting social distance towards unlabeled behaviors associated with withdrawn vs. disruptive autism with gender and country as between subjects factors revealed heightened stigma towards disruptive $(M=-.05, S E=.41)$ relative to withdrawn $(M=-2.86, S E=.40)$ behaviors, $F(1,289)=32.68$, $\eta^{2}=.10$, and no effect of gender or country ( $\left.p s>.06\right)$. When differences in the perceived dangerousness, responsibility, and commonness of behaviors associated with disruptive vs. withdrawn autism were added into the model, the main effect of withdrawn vs. disruptive behaviors remained apparent, $F(1,289)=32.68, \eta^{2}=.10$. An interaction between the difference in perceived dangerousness of withdrawn vs. disruptive autism and stigma was also observed, $F(1,289)=23.86$, $\eta^{2}=.08$. A trend toward an interaction between perceived commonness and stigma was observed, $p=.01$. No interaction between perceived responsibility and stigma was observed, $p=.14$.

We reran this analysis including only variables that had been significant (difference in perceived dangerousness) or marginally significant (difference in perceived commonness) in the prior analysis and adding cognitive empathy, openness, autism knowledge, and vertical orientation as covariates. An interaction between the difference in perceived dangerousness of withdrawn vs. disruptive autism and stigma remained apparent, $F(1,289)=13.39, \eta^{2}=.04$. A trend toward an interaction between stigma and perceived commonness, $p=.03$, also remained apparent. However, the main effect of withdrawn versus disruptive behaviors was no longer apparent $(p=.44)$. A main effect of vertical orientation, $F(1,285)=10.33, \eta^{2}=.04$, was observed.

\section{Discussion}

These findings align with our hypotheses by showing that university students who experience psychological conditions that are commonly perceived as dangerous to others (e.g., psychopathy, pain medication addiction, and schizophrenia) are more stigmatized than students with psychological conditions that are perceived as less dangerous to others (e.g., autism, ADHD, social anxiety, depression, and eating disorders). Also consistent with our hypotheses, disruptive behaviors associated with autism were perceived as more dangerous and elicited more desire for social distance than withdrawn behaviors. This pattern expands upon a large body of sociologically oriented research with general population samples that has focused on only a handful of mental illnesses and has revealed that substance abuse and schizophrenia are more stigmatized than depression (e.g., Griffiths et al. 2006; Jorm and Griffiths 2008; Lauber et al. 2004; Lee and Seo 2018; Link et al. 1999; Martin et al. 2000). The relatively low levels of stigma towards autism documented in the current study are generally consistent with the few prior studies that have compared stigma towards autism with stigma towards other conditions (Durand-Zaleski et al. 2012; Feldman and Crandall; Jensen et al. 2016). Our findings diverge from a recent study that found social distance towards autism to be numerically higher than social distance towards ADHD and LD (Huskin et al. 2018). However, the social distance scale used in that study was summed in a counterintuitive manner wherein rejecting more distant relationships contributed more heavily to the overall social distance score than rejecting closer relationships. This may have reflected confusion about how to adapt the Guttman scale used in early social distance research (which was not summed, as accepting a close relationship was assumed to indicate accepting all less intimate relationships) to the current practice of summing Likert scale responses toward different types of relationships (e.g., Angermeyer et al. 2005; Ouellette-Kuntz et al. 2010).

The current study extends upon recent research focused specifically on autism (Gillespie-Lynch et al. 2019) by demonstrating that heightened acceptance of inequality, reduced openness to experience, and lower cognitive empathy predict stigma towards a range of conditions. Consistent with research demonstrating that associations between perceived dangerousness and stigma are far more consistently observed than are associations between perceived responsibility and stigma (Angermeyer et al. 2011), the current study provides little support for the social attribution theory of stigma. Perceived responsibility did not mirror differences in social distance towards different conditions and was not significantly associated with autism stigma. In contrast, perceived dangerousness often mirrored social distance towards different conditions. Heightened perceived dangerousness and acceptance of inequality were also the only significant predictors of stigma towards both the label "autism" and behaviors associated with autism.

Although autism is increasingly the focus of attempts to understand and decrease stigma on college campuses, autistic university students (and students with other neurodevelopmental disorders) may face less stigma than students with diagnoses that are perceived as more dangerous to others. These findings should not be taken to imply that attempts to reduce stigma towards autism should cease, as autistic people report that stigma towards autism (e.g., the discriminatory behaviors that are believed to arise from negative stereotypes; Link and Phelan 2001) negatively impacts autistic people in myriad ways, including by reducing job prospects and decreasing psychological well-being (Johnson and Joshi 2016; Botha and Frost 2018). Instead these findings indicate that similar initiatives to those developed to reduce stigma towards autism are needed to help university students 
understand their peers with conditions that are perceived as more dangerous. The current findings also suggest that anti-stigma interventions focused on autism should not shy away from a discussion of the behavioral challenges that can be associated with autism. Such interventions should instead help people understand that these behavioral challenges often arise from difficulty communicating (e.g., Carr and Durand 1985) and may be best addressed by giving the person space to calm down and then developing strategies to promote more effective communication in collaboration with the autistic individual (Prizant and Fields-Meyer 2015; Waisman et al. 2020).

\section{Do Categorical Diagnostic Labels and/or Behaviors Contribute to Stigma?}

We hypothesized that behaviors associated with a given disorder would generally be more stigmatized than diagnostic labels (e.g., Gove 1975), but that diagnostic labels might be more stigmatized than behaviors when the label itself is associated with heightened perceived dangerousness (Link et al. 1987). Broadly consistent with our hypotheses, diagnostic labels were less stigmatized than behaviors for all conditions except psychopathy, mania, and learning disabilities. Psychopathy was the most stigmatized condition and the condition perceived as most dangerous to others, so the finding that the label psychopathy did not reduce stigma is consistent with our hypothesis. However, the lack of a difference in stigma towards the label "learning disability" and unlabeled behaviors associated with a learning disability was unexpected given that "learning disability" was the label that participants perceived as least dangerous. Although comparisons of the prevalence of all of the conditions examined in this report do not yet exist, existing research suggests that learning disabilities may be particularly common on university campuses (Burghardt et al. 2017). Therefore, the students' lack of differentiation between the label "learning disability" and the LD vignette may reflect accurate identification based on past experiences.

We had expected to find that behaviors that were paired with an explanatory diagnostic label would be less stigmatized than either labels or behaviors on their own. However, findings did not support this hypothesis; labeled behaviors were generally stigmatized to a similar degree as unlabeled behaviors. Nevertheless, adding the labels "autism" or "depression" to unlabeled vignettes depicting behaviors associated with each disorder did elicit reduced stigma. In contrast, the labels "psychopathy" and "pain medication addiction" contributed, albeit not significantly, to heightened stigma. The current findings align with later adaptations of labeling theory (e.g., Link et al. 1987) by indicating that disclosure is not a magic bullet that dissipates stigma towards all unusual behaviors. Instead labels appear to increase stigma towards conditions that are perceived as dangerous (e.g., psychopathy) and decrease stigma towards conditions that are not perceived as particularly dangerous (e.g., autism). The current findings also align with prior research (Matthews and Goldberg 2015; Ohl et al. 2017 Sasson and Morrison 2019) by suggesting that disclosing an autism diagnosis may reduce stigma.

\section{Which Individual Differences Predict Stigma Towards Varied Conditions?}

Aligning with recent autism specific research (GillespieLynch et al. 2019), acceptance of inequality emerged as a key predictor of stigma towards all of the conditions studied except psychopathy. Heightened cognitive empathy was also associated with significantly reduced stigma towards all conditions except the most stigmatized ones (psychopathy, pain medication addiction and schizophrenia). Intriguingly, heightened cognitive empathy was associated with heightened stigma towards psychopathy, suggesting that the ability to understand others' intentions makes people more accepting of most conditions but promotes wariness of conditions like psychopathy that are associated with potentially harmful intentions toward others. The current study is the first, to our knowledge, to demonstrate associations between reduced cognitive empathy and heightened stigma towards autism. It extends upon prior research linking reduced empathy to generalized prejudice (Bäckström and Björklund 2007) and to social distance towards depression and substance abuse, but not schizophrenia (Foster et al. 2018; Phelan and Basow 2007).

Aligning with prior research indicating that females typically report lower stigma than males (e.g., Corrigan and Watson 2007; Gillespie-Lynch et al. 2015), women reported lower stigma towards autism, eating disorder, social anxiety, ADHD and LD in the current study. Contrary to our hypotheses and to prior research (Obeid et al. 2015), students in Lebanon and US reported very similar levels of stigma towards the different conditions. The only significant country-level difference was in the opposite direction to what we had expected, finding reduced social distance towards people experiencing pain medication addiction among participants in Lebanon relative to the US. Our collaborators from Lebanon indicated that pain medications are distributed with fewer safeguards in Lebanon relative to the US. Given frequent discussion about the "opioid epidemic" in the US (e.g., Cerdá et al. 2013) and evidence that pain medication is accessible and commonly used in Lebanon (Ghandour et al. 2012), social norms may be more supportive of pain medication dependency in Lebanon relative to the US.

The lack of evidence that social distance towards autism is higher in Lebanon than the US is not consistent with the 
earliest comparison of stigma towards autism in Lebanon and the US (Obeid et al. 2015) but is largely consistent with a more recent study that found differences in stigma between students in Lebanon and the US were no longer apparent once other factors, including acceptance of inequality and openness, were accounted for (Gillespie-Lynch et al. 2019). This lack of consistency in country-level differences in stigma aligns with research indicating that country-level differences in personality tend to be weaker than individual differences within a country (Allik et al. 2017). It is also possible that stigma has increased in the US or decreased in Lebanon since the first study.

Social desirability bias was not associated with social distance towards most conditions, aligning with prior evidence that people may be relatively honest when sharing attitudes anonymously online (e.g., Gillespie-Lynch et al. 2019). Heightened social desirability bias was only associated with reduced stigma towards an unlabeled vignette depicting a schizophrenic university student. This finding may be relevant to the large body of sociological research examining stigma towards unlabeled vignettes depicting schizophrenia, typically through in-person interviews and without evaluating social desirability bias (e.g., Griffiths et al. 2006; Jorm and Griffiths 2008; Lauber et al. 2004; Link et al. 1999; Martin et al. 2000).

\section{Limitations and Future Directions}

Our reliance on university students in each country is a pronounced limitation of this and prior examinations of crosscultural differences in autism stigma (Obeid et al. 2015; Someki et al. 2018). Participants comprised only a small percentage of all undergraduates at the two universities from which our samples were recruited. Although we did not run power analyses prior to conducting this study, the sample sizes in this study and most research about attitudes toward autism (e.g., Gardiner and Iarocci 2014; GillespieLynch et al. 2015; Sasson et al. 2017; Tipton and Blacher 2014; White et al. 2016) are smaller than most sample sizes reported in sociological studies of mental health stigma (e.g., Angermeyer et al. 2013; Mehta et al. 2009). Sample size limitations, in conjunction with the large number of analyses conducted and resultant stringent alpha level, likely limited our power to detect effects.

Future work with more funding to support it should assess stigma across multiple settings in each country, preferably with general population samples. To resolve discrepancies between large scale general population studies that have revealed that attitudes towards certain conditions may be worsening (e.g., schizophrenia and other mental illnesses; Angermeyer et al. 2013; Mehta et al. 2009) and small scale studies with university students that suggest that attitudes toward autism may be improving (White et al. 2016), we need longitudinal general population studies that examine stigma towards varied conditions, including autism, across time and cultures. Anonymous surveys that include an assessment of social desirability bias may be useful for eliciting honest responses. However, research linking attitudes toward disabilities (e.g., social distance) with observed discriminatory behaviors would be particularly helpful for providing support for Link and Phelan's (2001) theoretical model of stigma. Such research should assess if regional differences in endorsement of negative stereotypes and enactment of discriminatory behaviors contribute to variations in mental health difficulties among neurodivergent people in specific communities. Longitudinal work should use consistent assessments across time to be able to evaluate if historical factors shift attitudes. In the current study, we utilized more varied response options for social distance scales than had been used in past research, potentially diluting our ability to detect country-level differences and making comparisons with prior time points impossible.

Given the relatively low alpha of the autism knowledge scale used in this study, future research should continue to improve autism knowledge measures. We recently developed a participatory autism knowledge measure in collaboration with autistic university students that has thus far exhibited better internal consistency $(\alpha=.84)$ than measures in the published literature (this knowledge measure is available open-access from the first author). Although guidance from a co-author with multiple disabilities improved the quality of the vignettes used in this study, future stigma research should be guided by input from diverse people representing each condition. Future research should also address stigma towards comorbid conditions, as the vast majority of autistic adults experience comorbid diagnoses (Vohra et al. 2017).

\section{Conclusions}

A primary recommendation derived from this research is that interventions are needed to decrease stigma towards disorders commonly perceived as dangerous to others (such as schizophrenia, which was highly stigmatized in this and past research), including explanations of why people with each condition act as they do and strategies to address potential challenging behaviors that may arise. Given that understanding others' perspectives was associated with numerically reduced stigma towards all conditions studied except psychopathy, trainings wherein people with specific diagnoses explain their motivations for acting as they do have potential to reduce stigma towards all conditions studied except psychopathy.

Prior work has demonstrated that online trainings are an efficient and cost-effective way to reduce stigma towards 
autism (e.g., Gillespie-Lynch et al. 2015). The current study suggests that online trainings are also needed to address stigma toward other disorders, including conditions like ADHD and depression that were as stigmatized as withdrawn autism in the current study, are common among university students more generally, and are often comorbid with autism (Antshel and Russo 2019; McMorris et al. 2019; Raue and Lewis 2011). To effectively exert systems change to counteract structural stigma, trainings need to be designed to reach all of the people on campus with whom neurodivergent students come into contact (e.g., students, faculty, counseling staff, residence life staff, librarians, tutors, etc.). Universities should invest in incentives so people are willing to engage meaningfully with such trainings. If resources are limited, train-the-trainer models could be used. Given that it would take a great deal of time to make and distribute online trainings about each disorder, and behaviors tend to be more stigmatized than labels, it might be most effective for educators to develop online trainings that help college students and faculty identify and understand reasons for atypical behaviors that may be shared across disorders.

Given that high-quality contact with diverse others is believed to be a particularly effective way to decrease stigma (Corrigan et al. 2007), mentorship programs wherein neurodivergent peers can engage with one another and with neurotypical peers in structured ways may be particularly effective at decreasing stigma. Opportunities for neurodivergent students to take on leadership roles in student government, student clubs, sports, and employment preparation activities alongside neurotypical peers are also likely to reduce stigma. Less prolonged strategies for inducing high quality contact, such as theatrical interventions, wherein autistic and non-autistic actors share their insights about autism with the broader community (e.g., Massa et al. 2020) and inter-group dialogue, wherein peer facilitators representing different identities lead dialogues about group membership, identity and social position and work through any conflicts that arise, are also promising for combatting stigma (e.g., Sakamoto and Pitner 2005). Interventions to make communities more supportive of neurodiversity should create increasingly immersive, entertaining, and participatory ways of addressing misconceptions and helping people understand why their neurodivergent community members behave as they do.

Acknowledgements We would like to thank all of the participants in this study.

Author Contributions KGL developed the idea for this study and played the leading role in survey design, analyses, the literature review and writing this manuscript. ND contributed substantially to survey design and editing this manuscript. RO contributed substantially to survey design and editing this manuscript. SR contributed substantially to survey design and edited this manuscript. SK wrote an early draft of this manuscript for her honors thesis. EG contributed to survey design and carefully edited this manuscript.
Funding This study received no funding.

\section{Compliance with Ethical Standards}

Conflict of interest The authors declare that they have no conflicts of interest.

\section{Appendix A}

\section{Labels}

1. College student with autism

2. College student with an eating disorder.

3. College student with social anxiety.

4. College student who is addicted to pain medication

5. College student with schizophrenia

6. College student with psychopathy

7. College student with depression.

8. College student with mania.

9. College student with ADHD

10. College student with a learning disability

\section{Vignettes}

\section{Disruptive College Student with Autism}

On the 1 st day of class, a student rushes in 15 min late. "I'm very sorry. I got lost." The student apologizes loudly, not looking at anyone in particular. The professor pauses in the lecture and waits for the student to take a seat. Once seated, the student pulls out a book and leafs through it intently until the topic of the lecture shifts. Suddenly, the student looks up and gazes at the professor with interest. The professor asks the class a question. The student calls out the correct answer without raising a hand. The professor asks the class another a question. The student again calls out the correct answer without raising a hand. The professor asks if anyone else would like to contribute to the discussion and asks another question. The student laughs and provides another correct answer but then begins to speak at length about a topic that seems only vaguely related to the question. The professor asks the student to give other students a chance to speak. The student stands up and hurries from the room calling back, "I'm sorry. I need a drink of water."

\section{Withdrawn College Student with Autism}

On the 1st day of class, a student walks in early and takes a seat as far as possible from the other students. The student 
gets out an iPad and stares at it intently. The student does not look around as other students take seats nearby. When another student's phone goes off, the student looks up, startled, and quickly blocks out the sound by putting their fingers in their ears. When the beeping stops, the student goes back to staring at the iPad, smiling and nodding down at the screen. When the professor begins lecturing, the student puts the iPad away but can't seem to help glancing down toward the bag where the iPad is kept during lecture. Each subsequent class, the student enters at almost exactly the same time, takes the same seat, gets out the iPad and then puts it away when the professor starts talking in almost exactly the same way as the student did on the 1st day of class. The student never asks questions but answers questions very carefully in an unusually formal tone of voice. Whenever the professor makes jokes or uses metaphors, the student does not show any evidence of understanding the jokes or metaphors. During breaks, the student never approaches other students and prefers instead to get out the iPad and stare down at it, nodding and smiling again.

\section{Addiction to Opioid Pain Medication}

On the 1st day of class, a sleepy-looking student with a blissful smile slowly walks into the classroom a few minutes late and slouches into the first available seat. The student's eyes are half-closed and the student's pupils appear unusually tiny. The student asks questions in a voice that is slightly slurred. At one point the student looks around distractedly and then begins to nod off. On subsequent days, the student often misses class or arrives late. The student sometimes mentions that it is difficult to get the right prescriptions for the chronic pain the student experiences. When present, the student typically enters the classroom smiling happily, but begins to look less cheerful part-way through the lecture. Soon, the student begins to appear uncomfortable and somewhat agitated. At this point the student often abruptly leaves the room with a bottle of water and a small bag. Upon returning to the classroom, the student is usually smiling again but breathing quite slowly.

\section{Attention Deficit Hyperactivity Disorder}

A student in your class seems constantly distracted and restless, often glancing out the window and doodling in the margins of notebooks. The student has little trouble understanding concepts and learning new terms in the class. However, when the professor calls on the student to answer a question, the student often asks the professor to repeat the question. The student frequently answers the question correctly, but immediately resumes fidgeting and doodling. The student appears somewhat more focused when participating in exercises with small groups of classmates, but begins to exhibit trouble concentrating if the group work lasts longer than five minutes.

\section{Bipolar Affective Disorder Type 1: Manic Episode}

A student walks into class on the 1st day and appears to be fairly similar to many other people in the class-nothing in particular about the student's personality, behavior, or appearance stands out. The student is polite and reasonably friendly, but perhaps a little reserved. From time to time the student contributes relevant and thoughtful comments to class discussions, but does not participate as frequently as some classmates and does not seem more enthusiastic about the course than the average student in the class. However, within a few weeks, the student is notably more engaged, confident, energetic, and excited about the topics addressed in class. The student is also more sociable with classmates. But before long, the student has become overly cheerful and frequently interrupts the professor during lectures with long, rambling, stream-of-consciousness comments that may or may not be relevant to the subject. The student has begun to speak incredibly rapidly and is sometimes hard to understand. After class, the student often stops the professor or classmates in order to continue talking. The student's speech is cheerful but seems compulsive.

\section{Depression (Moderate Depressive Episode)}

On the 1st day of class, a student seems cheerful, friendly, and interested in the course. The student is always punctual and well-groomed. However, by mid-semester the student practically seems like a different person. The student is frequently absent from class. When present, the student often shuffles in ten or fifteen minutes late looking poorly groomed and sad. The student, who had initially preferred to sit in the first row of desks near the center, now typically takes a seat in the back of the room closest to the door, rows away from classmates. The student rarely brings course materials to class and no longer takes notes or participates in discussion. One day, the professor asks the class to pass the essays due on this date to the front, but the student does not submit the assignment and appears neither surprised nor panicked. Though there are five minutes of class remaining, the student leaves early, not sticking around to receive information about the upcoming exam and not looking at anyone while leaving.

\section{Eating Disorder}

You go on a weekly class trip to an internship site. At lunchtime, everyone either eats something from home or buys something from the cafeteria. However, one student never eats during lunch. The student wears baggy clothes 
but is clearly very thin. The student talks or reads during lunch but sometimes looks around and watches other people eat. Whenever people ask if the student would like to share some of their food, the student thanks them but provides a reason for not being hungry and declines. One day, the student becomes very pale and has to lie down. The professor asks the student to eat something before returning to the class activity. The student at first declines and then when the professor insists, has a few bites very quickly. The student seems energized by the food but a few minutes after eating, the student goes into a bathroom. Although the student turns on a faucet, it sounds like the student is throwing up in the bathroom.

\section{Learning Disability}

A student in your class always arrives on time and prepared for class. The student sits in the front row and pays careful attention to the lecture. The student is an active participant in class discussions. The student always asks thoughtful questions that demonstrate insights about the lecture. The student also does well on multiple choice tests. However, the student struggles a great deal with writing. Even though the student spends a lot of time on each writing assignment, the student's writing always has numerous grammatical errors in it. In fact, it is sometimes difficult to understand the student's writing as the ideas in the student's writing often do not seem to follow each other in a clear way.

\section{Psychopathy}

A student walks confidently into class. The student appears confident and polished, and quickly establishes relationships with other students that make them feel uniquely understood. The student asks these other students to share their notes and completed homework and to do most of the work in group presentations. The students share their work willingly, feeling that the charismatic classmate they admire values their intelligence. The student likes to engage in debate and to ask daring questions that make everyone listen carefully. However, whenever it becomes clear that the student's position in a debate is weak, the student quickly switches sides in the debate and pretends to have always endorsed the correct position ("I was just playing devil's advocate!"). The student never admits to having been wrong. When the class watches a documentary about war crimes, the student laughs audibly at a segment about people being tortured. When others look surprised, the student pretends to have been coughing and fakes an expression of sorrow and pity for the victims of torture.

\section{Schizophrenia}

A student usually sits in the back of class silently with an expressionless face and a slouched posture. Sometimes the student suddenly sits up straight and giggles while staring at a blank space on the wall. When the professor calls on the student, the student responds very slowly in a voice that is as expressionless as the student's face usually is. Sometimes the words in the student's response are directly related to the professor's question. However, at other times the student's words sound like they are unrelated to one another or to the professor's question. During breaks, you sometimes see the student walking in circles in an empty hall talking conversationally as if to someone else, but no one else is there. One day the student stares in terror at a space on the wall in the classroom and then runs from the room.

\section{Appendix B}

1. Social distance scale (stigma)

1. I would NOT be willing to take a class with a student with $\mathrm{X}$

2. I would be willing to spend an evening socializing with someone with $\mathrm{X}$

3. I would NOT be willing to start a collaborative project with someone with $X$

4. I would be willing to make friends with a person with $\mathrm{X}$

5. I would NOT be willing to have a person with $X$ marry into the family

6. I would be willing to marry or date a person with $\mathrm{X}$

\section{References}

Allik, J., Church, A. T., Ortiz, F. A., Rossier, J., Hřebíčková, M., De Fruyt, F., et al. (2017). Mean profiles of the NEO personality inventory. Journal of Cross-Cultural Psychology, 48(3), 402-420.

American Psychiatric Association. (2013). Diagnostic and statistical manual of mental disorders (DSM-5®). Arlington: American Psychiatric Pub.

Angermeyer, M. C., Holzinger, A., Carta, M. G., \& Schomerus, G. (2011). Biogenetic explanations and public acceptance of mental illness: Systematic review of population studies. The British Journal of Psychiatry, 199(5), 367-372.

Angermeyer, M. C., \& Matschinger, H. (2005). Causal beliefs and attitudes to people with schizophrenia: Trend analysis based on data from two population surveys in Germany. The British Journal of Psychiatry, 186(4), 331-334.

Angermeyer, M. C., Matschinger, H., \& Schomerus, G. (2013). Attitudes towards psychiatric treatment and people with mental illness: Changes over two decades. The British Journal of Psychiatry, 203(2), 146-151. 
Antshel, K. M., \& Russo, N. (2019). Autism spectrum disorders and ADHD: Overlapping phenomenology, diagnostic issues, and treatment considerations. Current Psychiatry Reports, 21(5), 34.

Bäckström, M., \& Björklund, F. (2007). Structural modeling of generalized prejudice: The role of social dominance, authoritarianism, and empathy. Journal of Individual Differences, 28(1), $10-17$.

Bag, B., Yilmaz, S., \& Kirpinar, I. (2006). Factors influencing social distance from people with schizophrenia. International Journal of Clinical Practice, 60(3), 289-294.

Bakker, T., Krabbendam, L., Bhulai, S., \& Begeer, S. (2019). Background and enrollment characteristics of students with autism in higher education. Research in Autism Spectrum Disorders, 67, 101424.

Bogardus, E. S. (1933). A social distance scale. Sociology \& Social Research, 17, 265-271.

Botha, M., \& Frost, D. M. (2018). Extending the minority stress model to understand mental health problems experienced by the autistic population. Society and Mental Health. https://doi. org/10.1177/2156869318804297.

Boyle, M. P., Dioguardi, L., \& Pate, J. E. (2017). Key elements in contact, education, and protest based anti-stigma programs for stuttering. Speech, Language and Hearing, 20(4), 232-240.

Brosnan, M., \& Mills, E. (2016). The effect of diagnostic labels on the affective responses of college students towards peers with 'Asperger's Syndrome' and 'Autism Spectrum Disorder'. Autism, 20(4), 388-394.

Burghardt, J., Haimson, J., Lipscomb, S., Liu, A. Y., Potter, F., Waits, T., et al. (2017). National Longitudinal Transition Study 2012: Design Documentation. NCEE 2017-4021. National Center for Education Evaluation and Regional Assistance.

Carr, E. G., \& Durand, V. M. (1985). Reducing behavior problems through functional communication training. Journal of Applied Behavior Analysis, 18(2), 111-126.

Carré, A., Stefaniak, N., D’ambrosio, F., Bensalah, L., \& Besche-Richard, C. (2013). The Basic Empathy Scale in Adults (BES-A): Factor structure of a revised form. Psychological Assessment, 25(3), 679. https://doi.org/10.1037/a0032297.

Cerdá, M., Ransome, Y., Keyes, K. M., Koenen, K. C., Tracy, M., Tardiff, K. J., et al. (2013). Prescription opioid mortality trends in New York City, 1990-2006: Examining the emergence of an epidemic. Drug and Alcohol Dependence, 132(1-2), 53-62.

Connor, D. J. (2013). Kiss my Asperger's: Turning the tables of knowledge. International Journal of Inclusive Education, 17(2), $111-129$.

Corrigan, P. W., Larson, J., Sells, M., Niessen, N., \& Watson, A. C. (2007). Will filmed presentations of education and contact diminish mental illness stigma? Community Mental Health Journal, 43(2), 171-181.

Corrigan, P. W., Rowan, D., Green, A., Lundin, R., River, P., UphoffWasowski, K., et al. (2002). Challenging two mental illness stigmas: Personal responsibility and dangerousness. Schizophrenia Bulletin, 28(2), 293-309.

Corrigan, P. W., \& Watson, A. C. (2007). The stigma of psychiatric disorders and the gender, ethnicity, and education of the perceiver. Community Mental Health Journal, 43(5), 439-458.

DeNigris, D., Brooks, P. J., Obeid, R., Alarcon, M., Shane-Simpson, C., \& Gillespie-Lynch, K. (2018). Bullying and identity development: Insights from autistic and non-autistic college students. Journal of autism and developmental disorders, 48(3), 666-678.

Durand-Zaleski, I., Scott, J., Rouillon, F., \& Leboyer, M. (2012). A first national survey of knowledge, attitudes and behaviours towards schizophrenia, bipolar disorders and autism in France. BMC Psychiatry, 12(1), 128.

Eriksson, J. M., Andersen, L. M., \& Bejerot, S. (2013). RAADS- 14 Screen: Validity of a screening tool for autism spectrum disorder in an adult psychiatric population. Molecular Autism, 4, 49. https ://doi.org/10.1186/2040-2392-4-49.

Feldman, D. B., \& Crandall, C. S. (2007). Dimensions of mental illness stigma: What about mental illness causes social rejection? Journal of Social and Clinical Psychology, 26(2), 137-154.

Foster, S. D., Elischberger, H. B., \& Hill, E. D. (2018). Examining the link between socioeconomic status and mental illness prejudice: The roles of knowledge about mental illness and empathy. Stigma and Health, 3(2), 139.

Gardiner, E., \& Iarocci, G. (2014). Students with autism spectrum disorder in the university context: Peer acceptance predicts intention to volunteer. Journal of Autism and Developmental Disorders, 44(5), 1008-1017.

Gelbar, N. W., Shefcyk, A., \& Reichow, B. (2015). A comprehensive survey of current and former college students with autism spectrum disorders. The Yale Journal of Biology and Medicine, $88(1), 45$.

Gernsbacher, M. A. (2017). Editorial perspective: The use of personfirst language in scholarly writing may accentuate stigma. Journal of Child Psychology and Psychiatry, 58(7), 859-861.

Ghandour, L. A., El Sayed, D. S., \& Martins, S. S. (2012). Prevalence and patterns of commonly abused psychoactive prescription drugs in a sample of university students from Lebanon: An opportunity for cross-cultural comparisons. Drug and Alcohol Dependence, 121(1-2), 110-117.

Gillespie-Lynch, K., Brooks, P. J., Someki, F., Obeid, R., Shane-Simpson, C., Kapp, S. K., et al. (2015). Changing college students' conceptions of autism: An online training to increase knowledge and decrease stigma. Journal of Autism and Developmental Disorders, 45(8), 2553-2566.

Gillespie-Lynch, K., Daou, N., Sanchez-Ruiz, M. J., Kapp, S. K., Obeid, R., Brooks, P. J., et al. (2019). Factors underlying crosscultural differences in stigma towards autism among college students in Lebanon and the United States. Autism, 23(8), 19932006. https://doi.org/10.1177/1362361318823550.

Goffman, E. (1963). Stigma: Notes on the management of spoiled identity. New York: Simon \& Schuster Inc.

Gove, W. R. (1975). The labeling of deviance: Evaluating a perspective. New York: Sage.

Griffiths, K. M., Nakane, Y., Christensen, H., Yoshioka, K., Jorm, A. F., \& Nakane, H. (2006). Stigma in response to mental disorders: A comparison of Australia and Japan. BMC Psychiatry, 6(1), 21.

Haslam, N. (2000). Psychiatric categories as natural kinds: Essentialist thinking about mental disorder. Social Research, 67, 1031-1058.

Hinshaw, S. P., \& Stier, A. (2008). Stigma as related to mental disorders. Annual Review of Clinical Psychology, 4(1), 367-393.

Huskin, P. R., Reiser-Robbins, C., \& Kwon, S. (2018). Attitudes of undergraduate students toward persons with disabilities: Exploring effects of contact experience on social distance across ten disability types. Rehabilitation Counseling Bulletin, 62(1), 53-63.

Insel, T. R. (2014). The NIMH research domain criteria (RDoC) project: Precision medicine for psychiatry. American Journal of Psychiatry, 171(4), 395-397.

Jackson, D., \& Heatherington, L. (2006). Young Jamaicans' attitudes toward mental illness: Experimental and demographic factors associated with social distance and stigmatizing opinions. Journal of Community Psychology, 34(5), 563-576.

Jensen, C. M., Martens, C. S., Nikolajsen, N. D., Skytt Gregersen, T., Heckmann Marx, N., Goldberg Frederiksen, M., et al. (2016). What do the general population know, believe and feel about individuals with autism and schizophrenia: Results from a comparative survey in Denmark. Autism, 20(4), 496-508.

Johnson, T. D., \& Joshi, A. (2016). Dark clouds or silver linings? A stigma threat perspective on the implications of an autism diagnosis for workplace well-being. Journal of Applied Psychology, 101(3), 430. 
Jolliffe, D., \& Farrington, D. P. (2006). Development and validation of the Basic Empathy Scale. Journal of Adolescence, 29(4), 589-611. https://doi.org/10.1016/j.adolescence.2005.08.010.

Jones, R. S., Huws, J. C., \& Beck, G. (2013). 'I'm not the only person out there': Insider and outsider understandings of autism. International Journal of Developmental Disabilities, 59(2), 134-144.

Jorm, A. F., \& Griffiths, K. M. (2008). The public's stigmatizing attitudes towards people with mental disorders: How important are biomedical conceptualizations? Acta Psychiatrica Scandinavica, 118(4), 315-321.

Jorm, A. F., \& Oh, E. (2009). Desire for social distance from people with mental disorders. Australian and New Zealand Journal of Psychiatry, 43(3), 183-200.

Kapp, S. K., Gillespie-Lynch, K., Sherman, L. E., \& Hutman, T. (2013). Deficit, difference, or both? Autism and neurodiversity. Developmental Psychology, 49(1), 59-71.

Kenny, L., Hattersley, C., Molins, B., Buckley, C., Povey, C., \& Pellicano, E. (2016). Which terms should be used to describe autism? Perspectives from the UK autism community. Autism, 20(4), 442-462.

Kermode, M., Bowen, K., Arole, S., Pathare, S., \& Jorm, A. F. (2009). Attitudes to people with mental disorders: A mental health literacy survey in a rural area of Maharashtra, India. Social Psychiatry and Psychiatric Epidemiology, 44(12), 1087-1096.

Khawaja, M., \& Afifi-Soweid, R. A. (2004). Images of body weight among young men and women: Evidence from Beirut, Lebanon. Journal of Epidemiology \& Community Health, 58(4), 352-353.

Lauber, C., Nordt, C., Falcato, L., \& Rössler, W. (2004). Factors influencing social distance toward people with mental illness. Community Mental Health Journal, 40(3), 265-274.

Lee, M., \& Seo, M. (2018). Effect of direct and indirect contact with mental illness on dangerousness and social distance. International Journal of Social Psychiatry, 64(2), 112-119.

Link, B., Cullen, F., Frank, J., \& Wozniak, J. (1987). The social rejection of former mental patients: Understanding why labels matter. American Journal of Sociology, 92(6), 1461-1500.

Link, B. G., \& Phelan, J. C. (2001). Conceptualizing stigma. Annual Review of Sociology, 27, 363-385. https://doi.org/10.1146/annur ev.soc.27.1.363.

Link, B. G., Phelan, J. C., Bresnahan, M., Stueve, A., \& Pescosolido, B. A. (1999). Public conceptions of mental illness: Labels, causes, dangerousness, and social distance. American Journal of Public Health, 89(9), 1328-1333.

Link, B. G., Yang, L. H., Phelan, J. C., \& Collins, P. Y. (2004). Measuring mental illness stigma. Schizophrenia Bulletin, 30(3), 511-541.

Martin, J. K., Pescosolido, B. A., Olafsdottir, S., \& McLeod, J. D. (2007). The construction of fear: Americans' preferences for social distance from children and adolescents with mental health problems. Journal of Health and Social Behavior, 48(1), 50-67.

Martin, J. K., Pescosolido, B. A., \& Tuch, S. A. (2000). Of fear and loathing: The role of'disturbing behavior', labels, and causal attributions in shaping public attitudes toward people with mental illness. Journal of Health and Social Behavior, 41, 208-223.

Massa, A., DeNigris, D., \& Gillespie-Lynch, K. (2020). Theatre as a tool to reduce autism stigma? evaluating 'Beyond Spectrums'. Research in Drama Education: The Journal of Applied Theatre and Performance, 1-18.

Matthews, N. L., Ly, A. R., \& Goldberg, W. A. (2015). College students' perceptions of peers with autism spectrum disorder. Journal of Autism and Developmental Disorders, 45(1), 90-99.

McCrae, R. R., \& Costa, Jr, P. T. (2007). Brief versions of the NEOPI-3. Journal of Individual Differences, 28(3), 116-128.

McMorris, C. A., Baraskewich, J., Ames, M. A., Shaikh, K. T., Ncube, B. L., \& Bebko, J. M. (2019). Mental health issues in post-secondary students with autism spectrum disorder: Experiences in accessing services. International Journal of Mental Health and Addiction, 17(3), 585-595.

Mehta, N., Kassam, A., Leese, M., Butler, G., \& Thornicroft, G. (2009). Public attitudes towards people with mental illness in England and Scotland, 1994-2003. The British Journal of Psychiatry, 194(3), 278-284.

Morrison, K. E., DeBrabander, K. M., Faso, D. J., \& Sasson, N. J. (2019). Variability in first impressions of autistic adults made by neurotypical raters is driven more by characteristics of the rater than by characteristics of autistic adults. Autism. https://doi. org/10.1177/1362361318824104.

Nevill, R. E., \& White, S. W. (2011). College students' openness toward autism spectrum disorders: Improving peer acceptance. Journal of Autism and Developmental Disorders, 41(12), 1619-1628.

Obeid, R., Daou, N., Denigris, D., Shane-Simpson, C., Brooks, P. J., \& Gillespie-Lynch, K. (2015). A cross-cultural comparison of knowledge and stigma associated with autism spectrum disorder among college students in Lebanon and the United States. Journal of Autism and Developmental Disorders, 45(11), 3520-3536.

Ohl, A., Grice Sheff, M., Small, S., Nguyen, J., Paskor, K., \& Zanjirian, A. (2017). Predictors of employment status among adults with autism spectrum disorder. Work, 56(2), 345-355.

Ouellette-Kuntz, H., Burge, P., Brown, H. K., \& Arsenault, E. (2010). Public attitudes towards individuals with intellectual disabilities as measured by the concept of social distance. Journal of Applied Research in Intellectual Disabilities, 23(2), 132-142.

Pescosolido, B. A., Martin, J. K., Long, J. S., Medina, T. R., Phelan, J. C., \& Link, B. G. (2010). "A disease like any other"? A decade of change in public reactions to schizophrenia, depression, and alcohol dependence. American Journal of Psychiatry, 167(11), $1321-1330$.

Phelan, J. E., \& Basow, S. A. (2007). College students' attitudes toward mental illness: An examination of the stigma process 1. Journal of Applied Social Psychology, 37(12), 2877-2902.

Phelan, J., Link, B., Stueve, A., \& Pescosolido, B. (2000). Public conceptions of mental illness in 1950 and 1996: What is mental illness and is it to be feared? Journal of Health and Social Behavior, 41(2), 188-207.

Prizant, B. M., \& Fields-Meyer, T. (2015). Uniquely human: A different way of seeing autism. New York: Simon and Schuster.

Raue, K., \& Lewis, L. (2011). Students with disabilities at degreegranting postsecondary institutions. National Center for Education Statistics, US Department of Education, Statistical Analysis Report, 18.

Reavley, N. J., \& Jorm, A. F. (2011). Stigmatizing attitudes towards people with mental disorders: Findings from an Australian National Survey of Mental Health Literacy and Stigma. Australian \& New Zealand Journal of Psychiatry, 45(12), 1086-1093.

Reynolds, W. M. (1982). Development of reliable and valid short forms of the Marlowe-Crowne Social Desirability Scale. Journal of Clinical Psychology, 38, 119-125.

Sakamoto, I., \& Pitner, R. O. (2005). Use of critical consciousness in anti-oppressive social work practice: Disentangling power dynamics at personal and structural levels. The British Journal of Social Work, 35(4), 435-452.

Sasson, N. J., Faso, D. J., Nugent, J., Lovell, S., Kennedy, D. P., \& Grossman, R. B. (2017). Neurotypical peers are less willing to interact with those with autism based on thin slice judgments. Scientific Reports, 7, 40700.

Sasson, N. J., \& Morrison, K. E. (2019). First impressions of adults with autism improve with diagnostic disclosure and increased autism knowledge of peers. Autism, 23(1), 50-59.

Scheff, T. J. (1975). Labeling madness. Englewood Cliffs, NJ: Prentice-Hall.

Schomerus, G., Matschinger, H., \& Angermeyer, M. C. (2014). Causal beliefs of the public and social acceptance of persons with mental 
illness: A comparative analysis of schizophrenia, depression and alcohol dependence. Psychological Medicine, 44(2), 303-314.

Scior, K., Potts, H. W., \& Furnham, A. F. (2013). Awareness of schizophrenia and intellectual disability and stigma across ethnic groups in the UK. Psychiatry Research, 208(2), 125-130.

Someki, F., Torri, M., Brooks, P. J., \& Gillespie-Lynch, K. (2018). Stigma associated with autism among college students in Japan and the United States.Research in Developmental Disabilities, 76, 88-98. https://doi.org/10.1016/j.ridd.2018.02.016.

Soweid, R. A. E., Kteily, M. B. N., \& Rizkallah, M. C. S. (2002). Preoccupation with weight and disordered eating behaviors of entering students at a university in Lebanon. International Journal of Eating Disorders, 32(1), 52-57.

Stone, W. L. (1987). Cross-disciplinary perspectives on autism. Journal of Pediatric Psychology, 12(4), 615-630.

Sturm, A., \& Kasari, C. (2019). Academic and psychosocial characteristics of incoming college freshmen with autism spectrum disorder: The role of comorbidity and gender. Autism Research, 12(6), 931-940.

Tipton, L. A., \& Blacher, J. (2014). Brief Report: Autism awareness: Views from a campus community. Journal of Autism and Developmental Disorders, 44, 477-483. https://doi.org/10.1007/s1080 3-013-1893-9.

Triandis, H. C., \& Gelfand, M. J. (1998). Converging measurement of horizontal and vertical individualism and collectivism. Journal of Personality and Social Psychology, 74, 118-128. https://doi. org/10.1037/0022-3514.54.2.323.

Vohra, R., Madhavan, S., \& Sambamoorthi, U. (2017). Comorbidity prevalence, healthcare utilization, and expenditures of Medicaid enrolled adults with autism spectrum disorders. Autism, 21(8), 995-1009.
Waisman, T. C., Gassner, D., Gillespie-Lynch, K., Den Houting, J., Kapp, S., Nachman, B., et al. (2020). Autism Training for INSAR 2020 developed by INSAR's 2020 Autistic Researchers Committee.

Wei, X., Christiano, E. R., Yu, J. W., Blackorby, J., Shattuck, P., \& Newman, L. A. (2014). Postsecondary pathways and persistence for STEM versus non-STEM majors: Among college students with an autism spectrum disorder. Journal of Autism and Developmental Disorders, 44(5), 1159-1167.

Weiner, B., Perry, R. P., \& Magnusson, J. (1988). An attributional analysis of reactions to stigmas. Journal of Personality and Social Psychology, 55(5), 738-748.

White, D., Hillier, A., Frye, A., \& Makrez, E. (2016). College students' knowledge and attitudes towards students on the autism spectrum. Journal of Autism and Developmental Disorders. https ://doi.org/10.1007/s10803-016-2818-1.

Wright, A., Jorm, A. F., \& Mackinnon, A. J. (2011). Labeling of mental disorders and stigma in young people. Social Science \& Medicine, 73(4), 498-506.

Yap, M. B. H., Reavley, N., Mackinnon, A. J., \& Jorm, A. F. (2013). Psychiatric labels and other influences on young people's stigmatizing attitudes: Findings from an Australian national survey. Journal of Affective Disorders, 148(2-3), 299-309.

Publisher's Note Springer Nature remains neutral with regard to jurisdictional claims in published maps and institutional affiliations. 